group. Its function is neither prescriptive nor prohibitive. We would no more advocate proselytising than see spiritual concerns ousted from the clinical consultation.

We wish to make clear that we welcome the debate to which Poole et al are contributing and look forward to further discussion when Professor Poole will be talking at the Group's programme in October 2010 on 'Intolerant secularisation'. We do not look for uniformity of opinion, but we do hold that every viewpoint is worthy of consideration and respect.

Christopher C. H. Cook is Consultant Psychiatrist, Tees, Esk and Wear Valleys NHS Foundation Trust, and Professorial Research Fellow, Department of Theology and Religion, Durham University, email: c.c.h.cook@durham.ac.uk; Simon Dein is Consultant Psychiatrist, Princess Alexandra Hospital, and Senior Lecturer, University College London; Andrew Powell is former Consultant Psychotherapist and Honorary Senior Lecturer,

Oxfordshire Mental Healthcare Trust and University of Oxford; Sarah

Eagger is Consultant Psychiatrist, Central and North West London NHS

Foundation Trust, and Senior Lecturer, Imperial College London.

1 Poole R, Higgo R, Strong G, Kennedy G, Ruben S, Barnes R, et al. Concerns over professional boundaries remain unresolved. Psychiatrist 2010; eLetter (http://pb.rcpsych.org/cgi/eletters/34/2/63\#9866).

2 Koenig HG. Religion and mental health: what should psychiatrists do? Psychiatr Bull 2008; 32: 201-3.

3 Dein S, Cook CCH, Powell A, Eagger S. Religion, spirituality and mental health. Psychiatrist 2010; 34: 63-4.

4 General Medical Council. Personal Beliefs and Medical Practice - Guidance for Doctors. GMC, 2008.

5 Faulkner A. Knowing Our Own Minds. Mental Health Foundation, 1997.

6 McCord G, Gilchrist VJ, Grossman SD, King BD, McCormick KF, Oprandi AM, et al. Discussing spirituality with patients: a rational and ethical approach. Ann Fam Med 2004; 2: 356-61.

7 World Health Organization. WHOQOL and Spirituality, Religiousness and Personal Beliefs: Report on WHO Consultation. WHO, 1998.

doi: $10.1192 / \mathrm{pb} .34 .6 .257 \mathrm{a}$

\section{Divine intervention in mental health}

We thank Dein et al for opening up the debate about religion and its impact on mental well-being. This debate does not come a moment too soon.

We feel compelled to refute the suggestions that research unequivocally shows an association between religiosity and well-being. ${ }^{2}$ The research findings are wildly contradictory and it would be unreasonable to draw any firm conclusion on the basis of current knowledge. Furthermore, the research in this area is often biased, plagued by poor methodology (definitions of spirituality and religion are controversial, much variation exists between different faith groups, 'hidden' supportive measures of any community tend to be responsible for wellbeing rather than religion per se) and the research is almost invariably carried out by groups of researchers that have a vested interest in showing positive results for religiosity. The last point also applies to Dein and colleagues as they represent the Royal College of Psychiatrists' Spirituality and Psychiatry Special Interest Group. None of these points of contention is raised in the article.

In our personal experience we can come to think of a handful of patients that indeed seemed to have been consoled by religious beliefs, but hundreds of patients who have been tormented by fear of having transgressed some Bronze Age dogma about sexuality, having sinned in other ways or simply having taken their God's name in vain. A common sight on psychiatric wards is frightened patients shivering with fear when they hear what they perceive to be God's, not to mention Satan's, voice in their hallucinations. Some studies report that patients with schizophrenia and religious beliefs do indeed have worse long-term outcomes than patients with nonreligious delusions. ${ }^{3}$ The rigid cognitive belief system that underpins religious ideology plays straight into delusional beliefs that cause endless anguish, for example, 'If I break my pact with God (e.g. divorcing a violent husband, having sex out of wedlock), He will punish me'. Meeting such patients gives the concept of being 'God fearing' a whole new dimension. This commonplace suffering seems to have escaped the authors entirely.

Dein et al complain that there is a gap between patients' and psychiatrists' level of religiosity, the patients being more religious. Initially, this observation begs the question of whether religion could be part of the complex set of aetiological factors that constitutes the pathogenesis of mental illness in the first place and perhaps maintains it. Unquestioned belief in authorities always spells trouble, which recent events in the Catholic Church so amply exemplify. Some perturbed patients may find the certainties of religion tempting, but at what cost? Nevertheless, a good point is made that we must enquire more about the patient's religious beliefs as they can have a profound impact on lives from an early age. Yes, just think of the consistent mistreatment of women and children in some religions, beliefs in utterly unverifiable concepts (walking on water, miracles, angels with wings, devils, etc.) and the survival of your own death through an immortal soul, going to Heaven if you have been good but going to Hell if you have not. No wonder if you have a fragile mind that religious beliefs can push you over the edge.

We remind Dr Dein and his colleagues that instead of promoting private views, however strong and well meant they are, our traditional mandate as doctors is 'first of all, do no harm'. A more important question than whether the psychiatrist should pray with the patients or not - consider what this would entail if you had a Satanist under your care seems to us to be how religious groups systematically have targeted vulnerable psychiatric patients in an attempt to boost flagging numbers of their congregations. It is a despicable practice that pretends to offer lonely people a 'new family' for the 'minor cost' of believing in, and sometimes financially supporting, various belief systems of a more or less outrageous nature. It may be advantageous to a lonely or marginalised individual to find a ready-made group of accepting individuals with whom to associate, but religious groups do not have the monopoly on providing such solace. The issue of compassion is certainly not just the preserve of religious orders. So no, it is not 'time to move away from the old tendency to see religious and spiritual experiences as pathology'. But it is time to enquire in a respectful and gentle manner about patients' beliefs in general, not only religious ones, and for all, the psychiatrist should always remain the patient's foothold in a reality that often for them appears broken and fragile. Religious beliefs and practices may be helpful for some in terms of companionship and certainty, but clinical evidence indicates that for others 
they are sources of extreme distress and contribute to ongoing mental health problems.

1 Dein S, Cook CCH, Powell A, Eagger S. Religion, spirituality and mental health. Psychiatrist 2010; 34: 63-4.

2 Blazer DG. Religion, spirituality and mental health: what we know and why this is a tough subject to research. Can J Psychiatry 2009; 54 $281-2$

3 Doering S, Müller E, Köpcke W, Pietzcher A, Gaebel W, Linden M, et al. Predictors of relapse and rehospitalization in schizophrenia and schizoaffective disorder. Schizophr Bull 1998; 24: 87-98.

Lars K. Hansen Consultant Psychiatrist, Hampshire Partnership Trust, email: Ih4@soton.ac.uk, Nick Maguire Lecturer in Clinical Psychology, Southampton University.

doi: $10.1192 / \mathrm{pb} .34 .6 .258$

\section{Declarations of interest}

In their article on religion, spirituality and mental health, Dein et al make some important points. I was especially interested in 'enquiry into meaning' and some ways of handling prayer. But I wondered why they did not mention attachment theory, which has been used by Kirkpatrick ${ }^{2}$ to elaborate or explain many phenomena of religion.

I am left with one big question about declaration of interest. I thought it meant anything about us that might make us less of a 'disinterested' observer, researcher, etc. The four authors here declared 'none', so I found out more about them: one is a priest in the Church of England, one spent 7 years living in an orthodox Jewish community, one published in support of spirit release therapy.

I have no objection to how the authors spend their time outside their psychiatric jobs, but am I misunderstanding declaration of interest? I think that in the spirit of openness with us, and of 'disinterestedness' in relation to the subject of their article, those are important matters. That they were not disclosed leaves me ethically puzzled.

1 Dein S, Cook $\mathrm{CCH}$, Powell A, Eagger S. Religion, spirituality and mental health. Psychiatrist 2010; 34: 63-4.

2 Kirkpatrick LA. Attachment, Evolution, and the Psychology of Religion. Guilford Press, 2004

Peter Bruggen is Consultant Psychiatrist (retired), atheist, member of the British Humanist Association, London, UK, email: pbruggen@ blueyonder.co.uk

doi: $10.1192 / p b .34 .6 .259$

Authors' reply Peter Bruggen suggests that a declaration of interest is concerned with 'anything about us that might make us less of a 'disinterested' observer, researcher, etc.' However, instructions to authors on The Psychiatrist website indicate that: 'A Declaration of Interest must be given and should list fees and grants from, employment by, consultancy for, shared ownership in, or any close relationship with, an organisation or individual whose interests, financial or otherwise, may be affected by the publication of your paper.'

The clear emphasis here is on possible financial interests, although other 'close relationships' and interests are also mentioned. The problem is that if we take inclusiveness of the latter to an extreme, then all possible matters of deep concern, including our professional and academic interests and beliefs, as well as environmental, political, ethical and other concerns, as well as spiritual and religious beliefs, are potentially conflicts of interest. A cognitive-behavioural therapist involved in a trial of cognitive-behavioural therapy $v$. antidepressant treatment would have to declare a conflict of interests. A researcher studying any particular condition or disorder would have to declare an interest if they or their family had suffered from this condition, or if they treated any patients suffering from it in the course of their clinical work. In fact, arguably, anyone who publishes a paper on anything is far from 'disinterested' or else they would not be bothering to publish their paper.

But do we want thoroughly 'disinterested' people doing research, publishing papers or editing journals? Leaving aside for a moment the likelihood that none of us can claim to be completely objective about anything, is it not better that letters and papers are published by people who are deeply concerned to explore, research and express views which they hold dear? This does not mean that potential financial conflicts of interest should not be disclosed, as these arguably come into a different category. However, on matters such as spirituality, everyone has a perspective that is of interest. Being 'disinterested', if such a thing is possible, is just as much of a perspective as that of the atheist, humanist or religious person.

A distinction should be made between 'conflicts' of interest and 'perspectives' of interest. ${ }^{1}$ We did not consider that we had any conflicts of interest to declare in regard to our article. We hoped that our perspective of interest was sufficiently identified by the statement which indicated that we were writing on behalf of the Executive Committee of the Spirituality and Psychiatry Special Interest Group of the Royal College of Psychiatrists. Does not membership of this group self-evidently imply that we are interested in spirituality?

1 Cook CCH. Letter to the Editor. Addiction 2010; 105: 760-1.

Christopher C. H. Cook, Simon Dein, Andrew Powell, and Sarah Eagger doi: $10.1192 / p b .34 .6 .259 a$

\section{BNF limits v. threshold dosing}

David Taylor is right that there is excessive polypharmacy in routine practice. ${ }^{1}$ However, he does not examine or comment upon one of the root causes, British National Formulary (BNF) limits. Many clinicians seem to believe they are acting in the patient's interest by prescribing two compounds at close to the $B N F$ maximum rather than one above this mark. As a clinician it is commonplace to come across patients who respond well to sub-BNF doses as well as those who are untouched by a drug at the $B N F$ maximum dose. In the case of antipsychotic drugs, Agid et $a l^{2}$ have once again demonstrated that response to these drugs is related to the measured blockade of striatal receptors. As I suggested in my paper 12 years ago, ${ }^{3}$ this allows the clinician to quickly and accurately judge the sensitivity of an individual patient to antipsychotic treatment by increasing the dose rapidly to the point at which extrapyramidal side-effects are just discernible - and then waiting for a response. Following this threshold dosage scheme has led me to occasionally use a much wider range of doses than the $B N F$ limits allow. For example, I have prescribed risperidone in schizophrenia with good effect at as little as $0.5 \mathrm{mg}$ per day and as much as $32 \mathrm{mg}$ per day, a 64 -fold dose range. Although those who practise acute adult psychiatry often observe 